\title{
Consequences on port facilities of a tanker explosion
}

\author{
P. L. Metropolo ${ }^{1} \&$ A. E. P. Brown ${ }^{2}$ \\ ${ }^{I}$ Rhodia, Technology Research Centre, Brazil \\ ${ }^{2}$ Polytechnic College, University of Sao Paulo, Brazil
}

\begin{abstract}
The explosion scenario of a $30,000 \mathrm{~m}^{3}$ naphtha tanker that lay at anchor in port is simulated. The tanker geometry is enforced by a double steel plate, with the hazardous gas storage in the middle tanker containment. Baker's method was used to determine overpressures levels and damage distance from a potential confined vapour cloud explosion. The people vulnerability study at the port facility vicinity is also elaborated by using Probit equations. The explosion can be started by a simple electrostatic spark, human error, by sabotage or by acto of terrorism. Safety measures are recommended.

Keywords: risk analysis, fire, explosion, hazardous materials transportation, safety.
\end{abstract}

\section{Introduction}

Globalization has promoted an increase in the amount of hazardous materials transportation by road, air or sea. Great tankers transporting oil, petrochemical products and flammable gases, discharge these products in ports all over the world. At peace time this is a normal activity, but in conflict areas this simple activity may represent a great danger to port facility activities, its vicinity and materials that can result in a catastrophe. Besides process safety procedures, port security activities have also to be enforced in order to guarantee port safety. In Brazil, the International Ship and Port Security (ISPS) code regulations are attended to enhance maritime security, according to the International Maritime Organization (IMO) Diplomatic Conference of December 2002.

As accidents can happen, prevention studies can be performed to figure out fire or explosion damages extension. Risk analysis is a strong tool to help port 
safety and security. Consequence and vulnerability analyses are part of the risk analysis methodology [1, 2]. Baker's method [3] was applied to define physical impacts of the potential confined vapour cloud explosion. A vulnerability study was performed by using Probit [4] calculations to define the impact to port facility employees and to the near-by community. Finally, mitigation actions are recommended.

\section{Risk analysis}

Risk analysis methods are used to evaluate the confined explosion severity of naphtha reservoir installed inside a tanker. For confined vapour cloud explosions (CVCE) calculations model, we used Baker's method [3], which is a conservative approach, with added elements of the TNO multi-energy method [3]. Details of the method will not be described here. The method present results of the overpressure and impulse estimates due to the blast waves from the cylindrical reservoir rupture from pressurized gas, located at ground level. A ground level correction is also performed for the case studied. The method depends on the phase of the reservoir contents, its boiling point at ambient pressure, its explosion scenario critical and local temperatures and assumes that the flammable product combustion is complete.

\subsection{Explosion scenario description}

For the confined explosion scenario, it is assumed that the explosion will occur when the naphtha concentration inside the reservoir reaches the low flammable limit of $1.4 \% \mathrm{v} / \mathrm{v}$. To the calculations, naphtha is considered as n-pentane. The maximum explosion pressure of n-pentane in air of 8.7 bar gauge [5] is considered in the calculations. The naphtha reservoir geometry is $12 \mathrm{~m}$ high with a squared bottom of $10 \mathrm{~m}$. The gaseous phase volume of the naphtha reservoir is $1,200 \mathrm{~m}^{3}$.

\subsection{Calculation of the explosion energy}

To calculate the explosion pressure attenuation of the naphtha reservoir, it is considered the naphtha combustion reaction presented in equation 1:

$$
\begin{aligned}
& \mathrm{C}_{5} \mathrm{H}_{12}+{ }_{8} \mathrm{O}_{2}+\mathrm{N}_{2} \quad----\rightarrow \quad{ }_{5} \mathrm{CO}_{2}+{ }_{6} \mathrm{H}_{2} \mathrm{O} \quad+\mathrm{N}_{2} \\
& 1 \quad 8 \quad(0,79 / 0,21) \times 8 \quad 5 \quad 6 \quad(0,79 / 0,21) \times 8
\end{aligned}
$$

The naphtha combustion heat $(\Delta H)$ is $10,750 \mathrm{kcal} / \mathrm{kg}$. The internal energy varies according to equation 2 :

$$
\Delta U=\Delta H-\Delta P V
$$

The moles number variation before and after the combustion is 2 . The naphtha mass inside the reservoir will be calculated when it reaches the low flammable 
limit of $1.4 \% \mathrm{v} / \mathrm{v}\left(40,570 \mathrm{mg} / \mathrm{m}^{3}\right)$. For a reservoir of $1,200 \mathrm{~m}^{3}$ this corresponds to $48.7 \mathrm{~kg}$ of naphtha. The internal energy variation corresponds to the liberated energy from the explosion, which is shown in equation 3.

$$
\begin{aligned}
& \Delta U=-10,750 \frac{\mathrm{kcal}}{\mathrm{kg}}(48.7 \mathrm{~kg}) 1,000 \frac{\mathrm{cal}}{\mathrm{kcal}}-1.987(373)(2)= \\
& 5.23 \times 10^{8} \mathrm{cal}=2.2 \times 10^{9} \mathrm{~J}
\end{aligned}
$$

The explosion energy must be corrected to the ground reflection effect, because the naphtha reservoir is not above ground level. For this reason, the explosion energy must be duplicated, resulting in $4.4 \times 10^{9} \mathrm{~J}$. The input data to the Baker's method is shown in Table 1.

Table 1: $\quad$ Input data1.

\begin{tabular}{c|c}
\hline Description & Value \\
\hline Flammable substance & Naphtha $(\mathrm{n}$-pentane $)$ \\
\hline Local temperature $\left({ }^{\circ} \mathrm{C}\right)$ & 22.7 \\
\hline Tanker gaseous volume $\left(\mathrm{m}^{3}\right)$ & 1,200 \\
\hline
\end{tabular}

\section{Results}

The Baker's method calculation results are shown in Table 2. The resulting explosion overpressure attenuation is presented in Figure 1.

Table 2: $\quad$ Explosion overpressure results.

\begin{tabular}{c|c|c}
\hline \multicolumn{2}{c|}{ Physical Impact Description } & Value \\
\hline \multicolumn{2}{c}{ Naphtha Flammable Mass (kg) } & 48.7 \\
\hline \multirow{3}{*}{$\begin{array}{c}\text { Vapour Cloud Explosion } \\
\text { (VCE) }\end{array}$} & Distance to $3.84 \mathrm{kgf} / \mathrm{cm}^{2}$ & $20 \mathrm{~m}$ \\
\cline { 2 - 3 } & Distance to $0.53 \mathrm{kgf} / \mathrm{cm}^{2}$ & $40 \mathrm{~m}$ \\
\cline { 2 - 3 } & Distance to $0.3 \mathrm{kgf} / \mathrm{cm}^{2}$ & $60 \mathrm{~m}$ \\
\cline { 2 - 3 } & Distance to $0.16 \mathrm{kgf} / \mathrm{cm}^{2}$ & $100 \mathrm{~m}$ \\
\cline { 2 - 3 } & Distance to $0.07 \mathrm{kgf} / \mathrm{cm}^{2}$ & $160 \mathrm{~m}$ \\
\hline
\end{tabular}

$1 \mathrm{kgf} / \mathrm{cm}^{2}=10^{5}$ Pascal.

\subsection{Vulnerability results}

Eisenberg et al. [4] report the following Probit equations to:

Lung haemorrhage: $\operatorname{Pr}=-77.1+6.91 \times \ln (\mathrm{P})$

Eardrum rupture in humans: $\operatorname{Pr}=-15.6+1.93 \times \ln (\mathrm{P})$

where: $\mathrm{P}=$ peak overpressure, in Pascal or $\mathrm{kgf} / \mathrm{cm}^{2}$. 


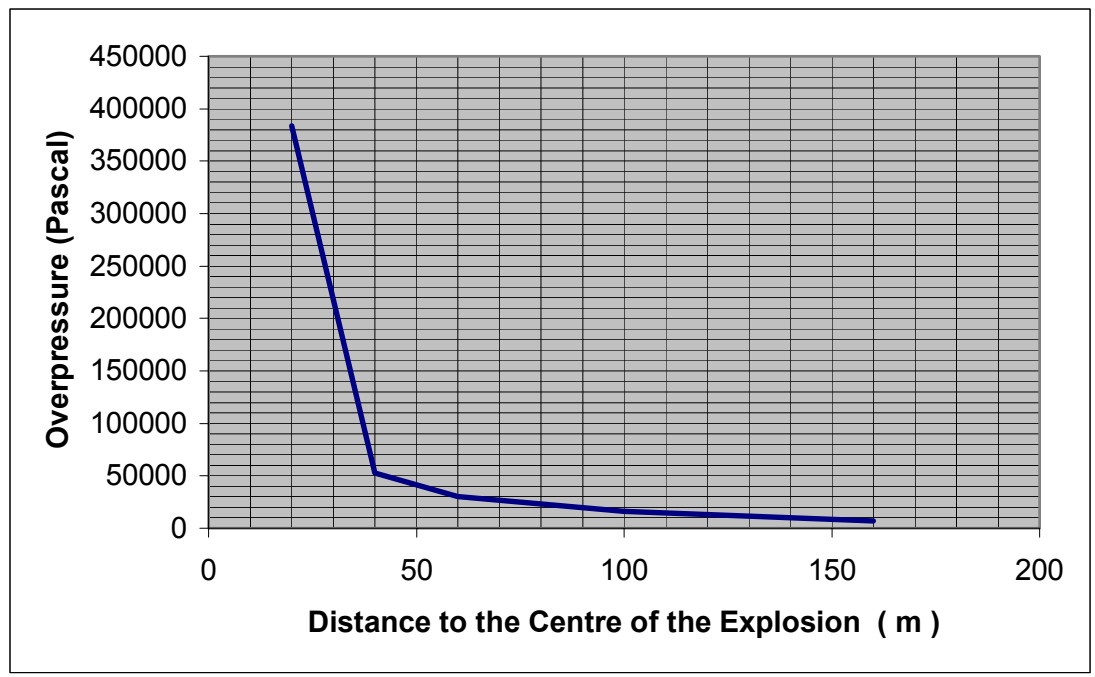

Figure 1: Overpressure attenuation graphic.

Table 3: Vulnerability results.

\begin{tabular}{|l|c|c|c|}
\hline \multicolumn{1}{|c|}{ Effect } & $\begin{array}{c}\text { Overpressure } \\
(\mathbf{k P a})\end{array}$ & $\begin{array}{c}\text { Probability } \\
(\mathbf{\%})\end{array}$ & $\begin{array}{c}\text { Distance } \\
(\mathbf{m})\end{array}$ \\
\hline Lung haemorrhage & 100 & 1 & 36 \\
\hline Eardrum rupture & 100 & 95 & 36 \\
\hline Eardrum rupture & 13.8 & 1 & 130 \\
\hline
\end{tabular}

\section{Mitigation and conclusions}

The port facility supervision work is very important to avoid security violations such as acts of terrorism or sabotage. Closed circuit TV (TVCC) with backup installed on port facility as well as intrusion supervision system are reliable systems against undesirable actions. On the process side, static electricity represents a hazard. Equipment must be earthed and the area of the tanker discharge must be electrically classified according to IEC norm 60079-10 [6].

To enhance port facility safety, the following documents must be prepared: risk analysis, security assessment, security plan and to appoint the port facility security officer.

The physical impact of the naphtha tanker explosion on port facility is equivalent to the mass of $940 \mathrm{~kg}$ TNT.

From Figure 1, it is concluded that the safe distance is normally considered at the overpressure peak of ca. $0.02 \mathrm{kgf} / \mathrm{cm}^{2}$. At this level, the probability $95 \%$ of no serious damage is $320 \mathrm{~m}$ from the tanker. At overpressure levels of $0.16 \mathrm{kgf} / \mathrm{cm}^{2}$ reparable damages to structures occur. Above this level, overpressure peaks results in the total destruction of buildings. With regards to 
human safety, the probability of lethality of $1 \%$ or $95 \%$ eardrum rupture from direct blast are reached at $36 \mathrm{~m}$ from the tanker and up to the distance of $130 \mathrm{~m}$ from the tanker, people can be thrown down to the ground that can cause secondary injuries.

\section{References}

[1] Lees, F.P. (1996) Loss Prevention in the Process Industries, $2^{\text {nd }}$ ed, v.1/2, Butterworth, Oxford, UK.

[2] Brown, A.E.P. (2004) Risk Analysis Study, S. Paulo/SP, Brazil.

[3] Yellow Book (1997) Methods for the Calculation of Physical Effects, Committee for the Prevention of Disasters, CPR 14E, TNO, $3^{\text {rd }}$ ed, The Hague, Netherlands.

[4] Eisenberg, N.A., C.J. Lynch and R.J. Breeding (1979) Vulnerability Model: A Simulation System for Assessing Damage Resulting from Marine Spills, Dept. of Transportation, Washington DC, USA.

[5] NFPA 68, (2002) Guide for Venting of Deflagrations, National Fire Protection Association, Quincy, MA, USA.

[6] IEC 60079-10 (2002) Electrical apparatus for explosive atmospheres Classification of hazardous areas, $4^{\text {th }}$ ed, EC. 